\title{
X comme XYLOGRAPHIE
}

Une « Biblia pauperum » ou Bible des pauvres (1460-1470)

\section{Daniel Bornemann}

\section{(2) OpenEdition}

\section{Journals}

Édition électronique

URL : https://journals.openedition.org/rbnu/1861

DOI : $10.4000 /$ rbnu. 186

ISSN : 2679-6104

Éditeur

Bibliothèque nationale et universitaire de Strasbourg

\section{Édition imprimée}

Date de publication : 1 mai 2014

Pagination : 80-81

ISBN : 9782859230524

ISSN : 2109-2761

Référence électronique

Daniel Bornemann, «X comme XYLOGRAPHIE », La Revue de la BNU [En ligne], 9 | 2014, mis en ligne le 01 mai 2014, consulté le 26 mai 2021. URL : http://journals.openedition.org/rbnu/1861 ; DOI : https:// doi.org/10.4000/rbnu.1861

\section{(c) (i) (2)(2)}

La Revue de la BNU est mise à disposition selon les termes de la Licence Creative Commons Attribution - Pas d'Utilisation Commerciale - Partage dans les Mêmes Conditions 4.0 International. 


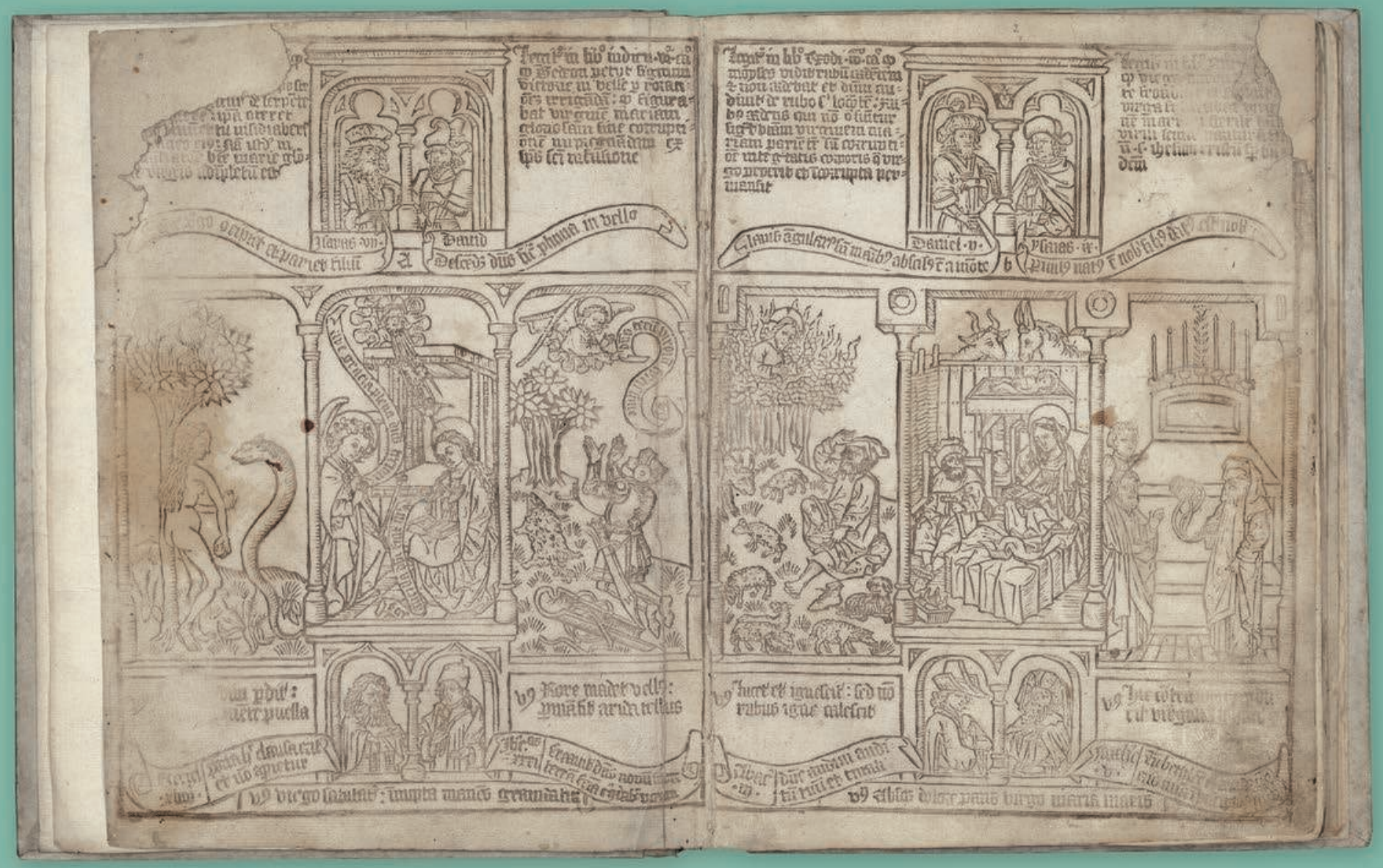


Trésors de l'écrit : un abécédaire

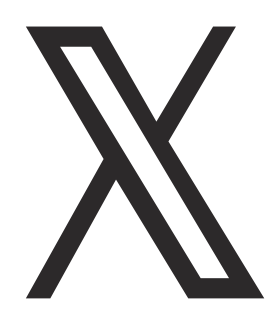

\title{
XYLOGRAPHIE
}

\author{
Une «Biblia pauperum 》 \\ ou Bible des pauvres (I460-I470)
}

On appelle « Bible des pauvres « de courts livrets, manuscrits ou imprimés, qui eurent au moyen-âge un grand succès, et dont la BNU a la chance de posséder un bel exemplaire xylographique. Basé sur le système de la typologie, qui met en rapport un événement du Nouveau Testament avec un ou plusieurs éléments de l'Ancien, ainsi qu'avec des paroles des prophètes, afin de mettre en évidence des liens, parfois assez subtils, entre ces diverses parties des Ecritures, ce type d'ouvrage a été répandu dans le monde germanique essentiellement, de la Hollande à l'Autriche, même si des modèles typologiques existent dans tout le monde chrétien, et ce depuis l'époque paléochrétienne.

Le texte, ou la Parole, et les images sont intimement liés dans ces livrets apparemment destinés à l'édification des chrétiens, mais l'érudition théologique en tant que telle y est aussi bel et bien présente, ne serait-ce que par l'indication chiffrée des passages de l'Ecriture, ou encore par l'emploi d'un latin très fortement abrégé et elliptique.

L'ampleur du succès de ces livrets est démontrée par le grand nombre d' " éditions " différentes, plus que par le nombre des exemplaires conservés, qui est très restreint. Le type auquel notre exemplaire appartient, dit à 40 feuilles (le nôtre est incomplet du tiers final), est connu en dix éditions différentes, qui ne diffèrent que par quelques détails infimes, parfois à peine visibles, comme des hachures différentes, des équilibres formels différenciés dans les ornements. Les motifs iconographiques et les textes sont parfaitement identiques à l'intérieur d'un type, les maladresses éventuelles des graveurs mises à part.

L'appellation de " Biblia pauperum " reste fort discutée. Il faut l'entendre non pas comme une Bible destinée aux classes déshéritées, aux pauvres, mais comme un document utilisé par les "pauvres prédicateurs ", ou moines mendiants, comme aide-mémoire, pour eux comme pour leur public, pour expliquer et mettre en rapport divers moments des livres bibliques. A l'époque de leurs paru- tions, ces livrets n'avaient pas de titre ; on les nommait de diverses manières : " concordantia historiarum ", " capitula Bibliae excerpta ", etc. L'appellation "Bible des pauvres " ne date que de la fin du $17^{\mathrm{e}}$ siècle, moment où les premiers incunabulistes s'intéressèrent à ce genre d'imprimés.

Rappelons que les textes sont gravés en même temps que l'image, sur une même planche de bois, caractère par caractère, et que l'impression est réalisée au recto uniquement des feuillets, au frotton, sans passage sous presse, avec une encre à base d'eau, différente de l'encre d'imprimerie. Certains livrets xylographiques ne comportent pas de texte imprimé : celui-ci est alors ajouté à la main par un copiste une fois les feuilles imprimées ; on les appelle alors des livrets chiro-xylographiques. Certains imprimeurs produisirent des "Bibles des pauvres" sur le principe d'une typographie accompagnée de bois d'illustration. La mise en couleurs de ces livrets est fréquente mais n'est pas de règle. La technique de la xylographie, gravure de textes entiers sur des planchettes de bois, s'est perpétuée plus longtemps qu'on ne le croit, jusqu'au $16^{e}$ siècle, car nombreuses sont les gravures d'illustration dans des livres imprimés typographiques où figure du texte, dans des phylactères par exemple. Mais les livrets entièrement xylographiques n'ont été produits qu'au milieu du $15^{\mathrm{e}}$ siècle, juste avant et juste après l'invention de l'imprimerie. Notre "Biblia pauperum " est datée de la décennie 1460-1470.

On estime à 600 le nombre total de livrets xylographiques conservés actuellement, entiers ou fragmentaires, dans les grandes bibliothèques du monde entier, tous titres et éditions confondus ; c'est dire la haute valeur patrimoniale de ces huit documents xylographiques (dont quatre sont des livrets) conservés à la BNU, témoignages de la production du livre au moment de l'invention de l'imprimerie.

\section{Daniel Bornemann}

